\title{
A Study on Self-efficacy and Its Role in Mobile-assisted Language Learning
}

\author{
Zhenyu Yang \\ Foreign Languages College, Inner Mongolia University, Hohhot, China
}

\begin{abstract}
In this era of digital technology, time and place no longer limit access to information, communication, and learning. Following the trend and popularity of CALL (Computer-assisted Language Learning), MALL (Mobile-assisted Language Learning) is gaining increasing attention and application. Many teachers as well as language learners turn to these mobile devices for various language learning purposes due to easy access to resources, convenience, and less language anxiety. Despite the comprehensive functions and sophisticated devices, a high percentage of learners still lag behind and even give up the apps after some time of use. Some research shows that the unsuccessful learners' lack of motivation constitutes a major hinderance in their self-regulated learning. This study tries to analyze an important component in learners' motivation, that is self-efficacy (especially computer self-efficacy), and seek for good solutions to the current problems.
\end{abstract}

Index Terms—mobile-assisted language learning, MALL, CALL, ESL, self-efficacy

\section{INTRODUCTION}

In the area of language learning, mobile devices are used to facilitate language acquisition in both informal and formal learning environments. Portable digital assistants (PDAs) and mobile phones have been the common devices used for educational purposes (Chinnery, 2006). Time and place no longer limit access to information, communication, and learning. In terms of learning, mobile devices have become a new and innovative learning platform for mobile learning, or m-learning. According to Kukulska-Hulme (2009), there is no one clear definition for m-learning. This is due to trying to define "mobility" in that this word can refer to either mobility of the device or of the learner; both are equally important when discussing m-learning.

Additionally, MP3 players and iPods (Demouy and Kukulska-Hulme, 2010) and hand-held video game devices (Kondo, Ishikawa, Smith, Sakamoto, Shimomura, and Wada, 2012) have also appeared in m-learning research. Currently, mobile devices with touchscreen capabilities such as smartphones and computer tablets have become the trend when it comes to mobile devices. Research on how tablets play a role in m-learning is gradually emerging (Chen, 2013; Yang and Xie, 2013). These touchscreen technologies provide instant access to the Internet, e-mail, and additional social media that include Twitter and Facebook. In addition to the Internet, a wide range of applications (apps) can be downloaded onto mobile devices to fit both the needs and interests of their users. However, due to these emergent technologies, the use of mobile devices as language learning tools is still being fully explored and remains an area of active research.

In many ESL (English as Second Language) classes, especially those in China, it is not rare to find a class made up of more than 50 students, preventing them from receiving individual assistances when needed. In addition, the limited class time - two to three hours per week - makes it impossible for the students to get immersed in the language. In that case, the teacher will have to seek ways to engage students in learning the language as much as possible outside the classroom. With the increasing use of mobile devices, many teachers as well as students turn to the modern technology for this purpose. However, technology alone cannot solve the problem. Despite the comprehensive functions and sophisticated devices, a high percentage of learners still lag behind and give up the apps after some time of use. As is said, technology becomes useful only when it is made good use of. Some research shows that the unsuccessful learners' lack of motivation constitutes a major hinderance in their self-regulated learning. This study tries to analyze an important component in learners' motivation, that is self-efficacy, and seek for good solutions to the current problems in the era of mobile assisted language learning.

\section{LITERATURE REVIEW}

\section{A. Learner Autonomy and Self-regulated Learning}

The study of autonomy and learning in education began with the work of Henri Holec in the 1970s (Godwin-Jones, 2011). Over 40 years later, autonomy is still an important pedagogical principle with continuing research to be conducted in this area. Holec defined learner autonomy as "the ability to take charge of one's own learning" (as cited in Cotterall, 2000, p. 109). Learner autonomy is a central concept for this research because the resource can encourage students to make their own learning decisions outside of the classroom.

Cotterall's 1995 study identified several learner beliefs that can influence learner autonomy: (1) beliefs about the role of the teacher, (2) students' learning goals, (3) the value of risk-taking, (4) the value of language learning experience, 
and (5) the value of self-confidence. Cotterall concluded that characteristics of autonomous learners included having expectations of the teacher as a facilitator, using self-monitoring techniques, having clearly established learning goals, taking more risks, having experience in language learning, and having greater self-confidence. Learner autonomy is a central concept in what has been called self-regulated learning.

Self-regulated learning is also referred to as self-instruction, "situations in which learners are working without the direct control of the teacher" (Dickinson, 1987, p. 11). According to Zimmerman (1998), self-regulated learners take full responsibility for their own learning and "believe academic learning is a proactive activity, requiring self-initiated motivational and behavioral processes as well as metacognitive ones" (p. 1). These processes employ techniques emerging from self-directed study, the first step towards self-regulated learning. In this stage, learners have their learning managed by teachers and other outside parties. This can be described as external regulation. They will consult and search for help, but are also fully aware of their need to be more responsible. Godwin-Jones (2011) states the purpose of self-directed study:

If they can learn how to build on existing knowledge, how to profit from errors, how to examine more closely the forms they are using, this can only have a salutary effect on their language ability and their capacity for autonomous learning. (p. 7)

In other words, this "capacity for autonomous learning" means that learners who reach an autonomous level control, manage, and implement their own learning tasks. Autonomous learning is the next step towards self-regulated learning.

There are three levels in a continuum of autonomy as discussed by Dickinson (1987): programmed learning, semi-autonomy, and autonomy. Programmed learning is the least autonomous stage of the continuum. During this stage, language instructors make every decision in the learning process, and the learners look to them for language materials, guidance, feedback, and instruction. This is where awareness is raised (Scharle and Szabó, 2000). The next stage, semi-autonomy, has both language instructor and learners sharing the responsibilities of the decision-making in order to promote autonomy. For example, learners may take a larger role in developing their own goals and evaluating their own progress. Attitudes begin to change and this stage is the longest of the three because it takes time for behaviors and attitudes to change from old habits and thoughts (Scharle and Szabó, 2000). The goal is to reach the autonomous stage. Learners in this stage begin making their own learning decisions and are closer to self-regulation. The roles are transferred from teacher to student and students begin to choose their own direction of study without the control of the teacher (Scharle and Szabó, 2000). In order for learners to progress towards their own autonomy, they need to learn to develop strategies that will help them to become confident in taking control of their own learning. One such strategy is the use of technology.

\section{B. Mobile-assisted Language Learning (MALL)}

(1) The Emergence of MALL

In the twenty-first century, smartphones, tablet computers, and other mobile devices have become common tools in an individual's daily life. Mobile-assisted language learning (MALL), a new subcategory of CALL, has emerged to take advantage of this new technology. This has led to new areas of research in how MALL can be implemented in language acquisition. The difference between CALL and MALL is portability and the importance of mobile devices is their ability to allow learners to choose what to study based on time and place. "The key attributes of mobile learning are identified as the potential for learning to be personalized, situated, authentic, spontaneous, and informal" (Kukulska-Hulme, 2009, p. 162). In correlation to these characteristics of mobile devices, a user's everyday situations can be seen as new learning opportunities (Pachler, 2009).

A study based on the previously mentioned key attributes was conducted by Kukulska-Hulme (2012). Her study identified how learners use mobile devices to learn. Her findings showed that the activities learners chose were based on time (spontaneous learning) and place (situated learning). In addition, learners were more motivated to learn via mobile devices due to easy access to resources, convenience, and less language anxiety. From the results of her study, Kukulska-Hulme developed a conceptual framework for mobile-supported language learning in informal settings (see Figure 1). The use of this framework for time and place dimensions, along with reflection on the purpose of devices, can help instructors' planning and designing match the needs of their students. This framework, which can be included in the techniques used in self-regulated learning, will determine the strength of influence on the fostering of autonomy within a language learner. According to Kukulska-Hulme (2007), there have been a variety of pilot studies and conferences on m-learning. Currently, there have been multiple studies conducted on mobile phone technology especially for vocabulary learning (Stockwell, 2007, 2010); However, as mobile technologies, especially smartphones and tablets, are introduced into more learning contexts, awareness of these learning tools will grow. Learning needs and the online resources will support ESL students in learning about the possibilities of MALL. 


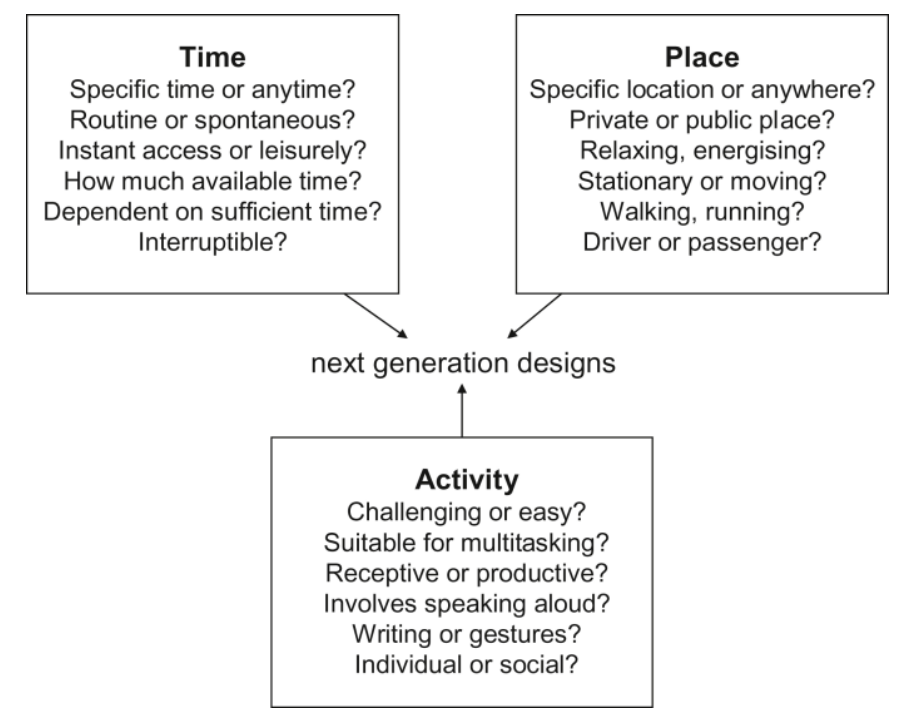

Figure 1. Conceptual framework for next generation designs for mobile-supported language learning in informal settings (adopted from Kukulska-Hulme, 2012)

(2) Problems with MALL

Studies have shown that participants have a positive response towards learning with mobile devices and are motivated by their use (Chen, 2013; Demouy and Kukulska-Hulme, 2010; Kondo et al., 2012; Mayberry et al., 2012; Stockwell, 2007). However, Kondo et al. (2012) found that once instructors stopped assisting the students, the students' self-study decreased. Demouy and Kukulska-Hulme (2010) also reported that some students might not even use their devices as a studying tool even if an instructor recommends it. It will take more than recommendations and suggestions to encourage self-study. "If MALL is to encourage students to spend more time on self-study, teacher mediation in learning may have to go beyond the preparation of MALL study materials" (Kondo et al., 2012). During the early stages of autonomy, instructor guidance is a necessary factor in facilitating the learning process towards self-regulation with the use of mobile devices. Students may need assistance in recognizing the value of their devices and they can become aware of this value in the classroom. If students can recognize this value, it can have a positive effect on their intrinsic motivation. According to Ellis (2008), "while it is probably true that teachers can do little to influence students' extrinsic motivation, there is a lot they can do to enhance their intrinsic motivation" (p. 5).

\section{Self-efficacy}

(1) Motivation and Self-efficacy

The word "motivation" refers to an inner drive that moves one to a particular action (Dornyei, 2001). According some studies, motivation plays a key part in deciding the learners' achievement in the language learning process. Gardner (1985) and Dornyei (2001) noted that, second language achievement is associated with language attitude, motivation, and anxiety. They did some further research to find that achievement and motivation have a great influence on each other, especially in some affective variables (Gardner, Masgoret, Tennant, \& Mihic, 2004).

Psychologist tried to define that constitute motivation (Dornyei, 2001). Of different theories, self-efficacy theory stands out since it is closely related to the confidence that a language learner gains during the learning process. According to Bandura (1993), people's cognitive performance is related to their self-efficacy, which is determined by one's previous performance, vicarious learning, verbal encouragement by others, and one's psychological reactions (e.g. pleasure or anxiety). That is to say, if people do not have a pleasant and rewarding experience in doing something, they may begin to doubt their ability to learn or succeed and may choose to give up. As Ames (1986) pointed out, successful learning is related to earners' beliefs and perceptions toward their own learning. A study by Tuckman and Sexton (1990) also disclosed a close connection between self-efficacy beliefs and academic achievements.

(2) Computer Self-efficacy

When it comes to language learning through the computer or mobile devices, study showed that computer self-efficacy plays a significant role in affecting learners' perceived usefulness, ease of use and attitude towards the online resources or apps, thus influencing the users' intention to continue using the resources.

Computer self-efficacy proves to constitute a key intrinsic drive in motivation. Computer self-efficacy is defined as reflecting the user's beliefs about "the confidence in one's ability to perform certain learning tasks using an e-learning system" (Pituch \& Lee, 2006, p. 226). Many studies show that computer self-efficacy has a significant influence on perceived ease of use (Davis, 1989; Park, 2009; Pituch \& Lee, 2006). Besides, Lim (2000) and Liaw (2008) also found that computer self-efficacy influences involvement of adult students in a web-based learning system. In terms of usefulness, computer self-efficacy remained one of the strong determinants in computer assisted language learning. In other words, students who think the system is more useful and have confidence in working on it are more likely to adopt the system. Hence, the language instructors and program developers should try to improve the content and function of the e-learning systems to attract them and encourage them to use the systems. 


\section{IMPROVING STUDENTS' SELF-EFFICACY IN MALL}

To help the language learners achieve a satisfying outcome, it is important to accelerate their self-efficacy, or to boost their confidence, making them believe in their abilities to learn by themselves and to succeed in the end. But how? As achievement and motivation affect each other, we may try using achievement to promote motivation. In that case, a better result functions as a kind of extrinsic motivation. Unlike intrinsic motivation, extrinsic motivation may not be considered so favorable (Brown, 1994). However, some studies indicate that it is actually a positive impetus. Deci and Ryan (1985) found that the extrinsic stimulus can be internalized to match the intrinsic motivation. Tuckman (1999) argued that without self-efficacy, one may not have the confidence to accomplish an action to achieve and even lose confidence to continue or just try. Without this "drive" (for example a better score in an exam), there is a shortage of energy to push that action.

According to some researchers (Ellis, 1994; Gardner, 1985), second language acquisition is a cyclic process: strong motivation, positive self-efficacy, and effective learning efforts may lead to increased academic improvements and feelings of progress, which can in turn enhance motivation and facilitate further effort. That is to say, helping the students or learners achieve a better academic outcome is an effective way to improve their motivation and then to promote progress.

For two terms, I talked or interviewed tens of teachers, students and administrators for their feedback to the use of the mobile devices in the language teaching and learning. I paid particular attention to their opinions on the long-term and better effect of this self-regulated learning. Here is a summary of my research:

In the first place, instructors and administrators should make every effort to improve the students' computer self-efficacy. Special stress should be put on boosting their self-confidence. Before the students are suggested to use the e-learning system, it is suggested that a training session should be arranged in the classroom or in the computer lab to familiarize them with the learning system. Such trainings enable the students to be more receptive of the self-learning environment and help to remove the technological problems that they may encounter during the learning process. If the students have difficulty accessing the system, they may feel reluctant to accept it or use it.

The interest in the app list has shown an apparent awareness of ESL apps amongst the students; therefore, it is recommended that the students should be provided with a more comprehensive list of apps available to them. As certain technologies become more common, it may take more than just providing these students with a resource. Instructor guidance has shown to be an important factor in self-directed study, and implementation of these technologies might come to be a common tool in classrooms and instruction in the future, much like how computers are now. There is no denying that the influence and importance technology has become in an individual's life; therefore, taking advantage of technology's learning potential can be used as a tool in the direction towards self-regulation.

In the second place, so as to increase the students' acceptance and adjust to the development in technology, the system in these mobile devices should be developed to target changes in perceived usefulness. The instructors or administrators can then demonstrate to the students how the system would benefit the students' learning process and help to ease the grasp of the learning content. Therefore, it is critical that the system should be designed up-to-date and user-friendly.

One of the great advantages of MALL is that the learners can download and use many different learning apps instead of online platforms. Apps can engage students with entertaining and interactive activities that provide immediate feedback. Additionally, many apps are cheap or free and thus affordable to many students. These characteristics of apps can play a role in the changing of attitudes and the increasing of a student's intrinsic motivation. Based on Ellis' quote, apps can be one way for teachers to enhance students' intrinsic motivation.

After a summary of the current popular apps, I categorize them into three sets: the English skill apps, the test preparation apps and the productivity apps. The English skill apps include apps related to the categories of grammar, listening, pronunciation, reading, speaking, spelling/phonics, vocabulary, and writing. The test preparation apps are those for such tests as GRE, IELTS, TOEFL and CET (College English Test in China) etc. that prepare learners for a certificate or entrance to further studies. Finally, the productivity apps help students organize, plan, prepare, and be more productive with their studies and in class. The apps are categorized as dictionaries, homework scheduling, note-taking, translation, and typing. The instructors or administrators are supposed to sort out the appropriate apps in each category before recommending them to the students.

In the third place, the students or learners are encouraged to join MALL-related activities or groups to help each other and learn together. According to Chen (2013), student-centered activities and collaboration are fundamental to the increased opportunities for learners to take more responsibility for their studies. Collaboration is a social activity that can foster the development of self-regulated learning. In other words, the students need guidance for self-directed study to bring awareness to the learning potentials of their mobile devices because they are already using them in their everyday lives. They just need to be provided with more guidance, collaborative opportunities, and resources to further support their learning needs. Therefore, it is necessary to understand how this student population uses their mobile devices to, at the very least, direct them to the resources that can better assist them with their mobile learning needs. Since the English program, such as the ELP programs at many universities, encourages student self-directed study through resources such as the self-learning center, the teacher's goal is to become an additional resource to support this student population. It is important to promote current resources to students to help them develop their own learner autonomy in response to changing technologies. 
On the other hand, some teachers, especially those who have some trouble learning the new technology, expressed their concerns in mastering these apps, not to say guiding the students. It is therefore critical to ease the anxiety of both the teachers and the learners. Besides developing a system that is more usable and user-friendly, it is also a good idea to ask some students who have grasped the apps as teaching assistants or just to share their experience with both the teacher and their fellow learners.

\section{DISCUSSION}

With the popularity and wide use of mobile devices, it is inevitable that they are applied in the teaching and learning environment. Despite their flexibility and fast feedback in facilitate mobile assisted language learning, special emphasis should be placed on the learners' motivation and experience to help them obtain a sense of fulfillment. Self-efficacy, especially computer self-efficacy, can play a significant role in realizing this. In Mobile-assisted Language Learning, the teachers as well as the students and administrators should take this factor into serious consideration for a better result and persistent use of the apps. A good technology should attract the users to keep using it.

There is much to explore in the area of MALL. This research is conducted only through literature summary and some talks and interviews, more empirical studies need to be conducted to further research the role that self-efficacy plays and its correlation with MALL.

\section{REFERENCES}

[1] Chen, X. (2013). Tablets for informal language learning: Student usage and attitudes. Language Learning \& Technology, 17(1), 20-36. Retrieved from http://lt.msu.edu/issues/february2013/chenxb.pdf (accessed 10/10/2019).

[2] Chinnery, G. M. (2006). Going to the MALL: Mobile assisted language learning. Language Learning \& Technology, 10(1), 9-16. Retrieved from http://llt.msu.edu/vol1 onum1/ emerging/ (accessed 03/11/2019).

[3] Churches, A. (2009). Bloom's Digital Taxonomy. Retrieved from http://edorigami.wikispaces.com/file/view/bloom\%27s\%20Digital\%20taxonomy\%20v3.01.pdf/65720266/bloom\%27s\%20Digi tal\%20taxonomy\%20v3.01.pdf (accessed 28/09/2019).

[4] Cotterall, S. (1995). Readiness for autonomy: Investigating learner beliefs. System, 23(2), 195-205.

[5] Cotterall, S. (2000). Promoting learner autonomy through the curriculum: Principles for designing language courses. ELT Journal, 54(2), 109-117.

[6] Demouy, V. \& Kukulska-Hulme, A. (2010). On the spot: using mobile devices for listening and speaking practice on a French language programme. Open Learning, 25(3), 217-232.

[7] Dickinson, L. (1987). Self-instruction in language learning. London: Cambridge University Press.

[8] Dornyei, Z. (2001). Teaching and researching motivation. Essex, England: Pearson Education.

[9] Ellis, R. (1994). Where CAI is effective: A summary of the research. Electronic Learning, 3, 82-84.

[10] Ellis, R. (2008). Principles of instructed second language acquisition. CAL Digest. Retrieved from http://www.cal.org/resources/digest/digest_pdfs/Instructed2ndLangFinalWeb.pdf (accessed 26/11/2019).

[11] Gardner, R.C. (1985). Social psychology and language learning: The role of attitude and motivation. London: Edward Arnold.

[12] Gardner, R.C., Masgoret, A.M., Tennant, J., \& Mihic, L. (2004). Integrative motivation: Changes during a year-long intermediate-level language course. Language Learning, 54(1), 1-34.

[13] Godwin-Jones, R. (2011). Emerging technologies: Autonomous language learning. Language Learning \& Technology, 15(3), 4-11 Retrieved from http://llt.msu.edu/issues/october 2011/emerging.pdf (accessed 19/09/2019).

[14] Kern, R. (2006). Perspectives on technology in learning and teaching languages. TESOL Quarterly, 40(1), 183-210.

[15] Kondo, M., Ishikawa, Y., Smith, C., Sakamoto, K., Shimomura, H., \& Wada, N. (2012). Mobile assisted language learning in university EFL courses in Japan: developing attitudes and skills for self-regulated learning. ReCALL, 24(2), $169-187$.

[16] Kukulska-Hulme, A. (2007). Mobile usability in educational contexts: what have we learnt? International Review of Research in Open and Distance Learning, 8(2). Retrieved from http://www.irrodl.org/index.php/irrodl/article/viewArticle/356 (accessed $10 / 11 / 2019)$.

[17] Kukulska-Hulme, A. (2009). Will mobile learning change language learning? ReCALL, 21(2), 157-165.

[18] Kukulska-Hulme, A. (2012). Language learning defined by time and place: A framework for next generation designs. In J. E. Diaz-Vera (Ed.), Left to my own devices: Learner autonomy and mobile-assisted language learning (pp. 3-20). Bingley, UK: Emerald Group Publishing Limited.

[19] Mayberry, J., Hargis, J., Boles, L., Dugas, A., O’Neill, D., Rivera, A., \& Meler, M. (2012). Exploring teaching and learning using an iTouch mobile device. Active Learning in Higher Education, 13(3), 203-217.

[20] Mitchell, K., Beddes, S., Gafurov, K., Hull, L., Jamieson, J., Othman, M., Reyes, V., \& Scholz, M. (2012). iPads in ESL classrooms. Retrieved from https://itunes.apple.com/us/book/ ipads-in-esl-classrooms/id569315628?mt=11 (accessed 06/11/2019).

[21] Pachler, N. (2009). Research methods in mobile and informal learning: some issues. In G. Vavoula, N. Pachler, \& Kukulska-Hulme, A. (Eds.), Researching mobile learning (pp. 1-15). Oxford: Peter Lang AG.

[22] Reeves, B. \& Nass, C. (1996). The media equation: How people treat computers, television, and new media like real people and places. Standford, CA: Cambridge University Press.

[23] Scharle, A. \& Szabó, A. (2000). Learner autonomy: A guide to developing learner responsibility. Cambridge: Cambridge University Press.

[24] Siltanen, R. (2011, December 14). The real story behind Apple's 'Think Different' campaign. Forbes. Retrieved from http://www.forbes.com/sites/onmarketing/2011/12/14/the-real-story-behind-apples-think-different-campaign/ R (accessed 20/10/2019). 
[25] Stockwell, G. (2007). Vocabulary on the move: investigating an intelligent mobile phone-based vocabulary tutor. Computer Assisted Language Learning, 20(4), 365-383.

[26] Stockwell, G. (2010). Using mobile phones for vocabulary activities: examining the effect of platform. Language Learning \& Technology, 14, 95-110. Retrieved from http://lit.msu.edu/vol14num2/default.html (accessed 10/11/2019).

[27] Yang, C. \& Xie, Y. (2013). Learning Chinese idioms through iPads. Language Learning \& Technology, 17(2), 12-23. Retrieved from Retrieved from http://lt.msu.edu/issues/June2013/yangxie.pdf (accessed 19/11/2019).

[28] Zimmerman, B. J. (1998). Developing self-fulfilling cycles of academic regulation: An analysis of exemplary instructional models. In D. H. Schunk \& B. J. Zimmerman (Eds.), Self-regulated learning: From teaching to self-reflective practice (pp. 1-19). New York: The Guilford Press.

Zhenyu Yang is an associate professor at Foreign Languages Department of Inner Mongolia University. His main research interests are computer-assisted language learning, TESOL and corpus linguistics. He did research in the United States as a visiting scholar for one year. 